\title{
Pre-release access to official statistics: The case of Finland
}

\author{
Marjo Bruun ${ }^{\mathrm{a}, *}$ and Heli Mikkelä ${ }^{\mathrm{b}}$ \\ ${ }^{a}$ Statistics Finland, FI-00022 Statistics Finland, Finland \\ ${ }^{\mathrm{b}}$ National Audit Office of Finland, FI-00101 Helsinki, Finland
}

\begin{abstract}
The article discusses the nature of release practices, the ways to support the users of statistical information, and the challenges the statistical offices are facing in the complex data ecosystem. In Finland the simultaneous release of new statistical information to all users, based on the European Statistics Code of Practice, has been widely accepted and is currently considered "the norm". The principle of impartiality and simultaneous releasing is also widely respected by politicians, the media, and other decision-makers and users. However, currently the issue of release practices is growing more multidimensional as the data ecosystem is changing and the statistical offices are adapting to the changes. What kinds of rules and principles are to be applied to data deliveries or analyst services, or other products not recognised as official statistics?
\end{abstract}

Keywords: Prerelease, release, official statistics, confidentially, trust, data ecosystems, Code of Practice

\section{Introduction}

For statistical offices one of the key principles of official statistics is impartiality. The offices apply this principle in a number of ways. The simultaneous release of new statistical information to all users is one of the most essential ways.

Currently, the issue of release practices is growing more multidimensional as the data ecosystem - including all the actors and organisations dealing with data, the entire system of processes, data and interactions is changing. As the statistical offices are adapting to the changes, new questions arise: What kinds of rules and principles are to be applied to data deliveries or analyst services, or other products not recognised as official statistics?

In the following section, we present different views, perspectives - or stories - related to the embargo, prerelease and user service of statistics and statistical information. These cases are based on experiences from Statistics Finland, discussions with various information

${ }^{*}$ Corresponding author: Marjo Bruun, Statistics Finland, FI-00022 Statistics Finland, Finland. Tel.: +358 29551 3055; E-mail: marjo. bruun@stat.fi. producers and information users, on assessments of current practices during the peer review of the European Statistics Code of Practice and on other evaluations carried out during recent years.

\section{The current state of the art: No embargo}

The first perspective is the current "state of the art" in Finland. "Pre-release or embargo - no, absolutely not, they do not exist. No, nobody gets the statistical figures in advance". This is how journalists answered when asked about the pre-release practices in Finland some years ago during the peer review of the European Statistics Code of Practice.

This answer still describes the situation in Finland quite well. According to the principles of national official statistics - in line with the European Statistics Code of Practice - the official statistics are to be published simultaneously to all users.

The same rules apply to media conferences. Embargo is allowed only when the media conference is about something different than new statistical figures - for example, when the results of a specific study or project are published. 
The simultaneous release of new statistical information has been widely accepted and is currently considered "the norm". The media, politicians and other decision-makers respect the principle of impartiality, and that of simultaneous release. The acceptance is very much due to long-time communication about the principles, and very strict compliance - with no exceptions or slips.

Sometimes, the issue is also discussed internally in the statistical office as clearly a certain tension exists between strict statistical disclosure decisions and an agile, user-oriented service. According to the decision on publishing, the statistical information is made public only when it has been published on the website of Statistics Finland. The standard release time is 8 o' clock in the morning. In case of technical problems, the actual release on the websites overrules the pre-set release time. This has sometimes led to internal discussions as some experts find it a bit embarrassing that even though the figures are ready to be published. They cannot be given to the audience as they are not yet visible on the website. However, these cases appear very seldom.

To conclude, the statistical principles are highly appreciated, and in the statistical office there is a strong will and persistency to maintain the status quo. The rules and principles are clear and provide a firm base upon which to act.

\section{Support to users in the real-time, fast-acting data climate}

The second perspective includes the occasions where the current non-embargo practice is being questioned, and how these occasions have been managed. The issue is usually raised by the media wishing to have time to edit their news and stories, or by politicians wishing to have time to get prepared for questions from the media. The most common reasons or explanations for the need to get the statistical figures in advance under embargo are expressed as urgency and hurry.

The principles of official statistics state that embargo is possible or can be used, but if so, the practices must be clearly stated and transparent. (However, as stated previously, in Finland so far the answer has been "no embargo to official statistics".)

Every now and then the question of a limited prerelease is discussed. However, if a limited or restricted pre-release or embargo were to be implemented, some very difficult and even cumbersome questions would most likely soon arise: To whom will embargo be granted, when, on what condition - and what will happen if the embargo is broken? - These questions are subject to various interpretations and could lead to very complicated and delicate situations including tensions, contradictions and potential conflicts.

To politicians' or ministers' claim for embargo the answer could promptly be: "If you cannot react and answer fast, and if you cannot take criticism when the figures do not support your promises, you should probably reconsider your choice of career. Being exposed to challenges is an essential part of the work of a politician."

In discussions with representatives of the media, anti-embargo comments have also been presented. The leader of one of the main Finnish media companies, the Finnish Broadcast Company, considered a possibility of embargo unnecessary. In the current fast, online, hectic, real-time media landscape journalists and other data users must be able to react to all kinds of pieces of information fast and flexibly, statistical information making no difference in respect to the demand. This is especially true in the media climate where the media are increasingly competing in speed and titles. In this kind of a world the risk and likelihood of the embargo being broken is high as the main modus operandi is the opposite.

In order to help the media to communicate and users to understand statistical figures correctly, Statistics Finland has, instead of embargo, introduced a couple of ways to work with them. First, "pre-coaching" sessions for journalists prior to some of the main releases have been introduced. During these sessions, journalists are given background information and the concepts, terms and previous development of the phenomena are explained. The feedback has been quite positive. These kinds of briefing practices are presumably - or at least should be - a part of the tasks of cabinets of ministers and politicians, too. Another question is how the National Statistical Offices (th NSOs) could or should promote the statistical literacy of the staff of these cabinets.

Another pilot recently introduced is called "chat with the expert" sessions on Twitter. During these sessions, the expert answers users' questions for a couple of hours on line immediately after the actual release. This practice has also been welcomed by the audience.

\section{Confidentiality and internal pre-release within NSOs and ONAs}

The third perspective to pre-release and embargo is related to internal practices within the organisations 
producing official statistics - NSOs and other national agencies producing statistics (ONAs). It is brought up here even though - strictly speaking - in these cases, we are not actually speaking about embargo or prerelease, but rather about the internal management and confidentiality practices.

In statistical offices, the roles and responsibilities, as well as the practices concerning the right to manage, handle and see data and statistical figures have customarily been quite clear. Especially when it comes to confidential data, sensitive data or information affecting the economic situation and markets, the procedures have included confidentiality checks, commitments of confidence and identification of licensed parties within the organisation and - when relevant - among subcontractors or partners.

When it comes to organisations whose main task is not the production of statistics, but for which the statistical department or function is one of the "sidefunctions", the situation can appear different. What are the rights and responsibilities of the top management, what kinds of procedures and practices take place to secure statistical confidentiality and prevent leakages or accidental pre-release in these cases? Are internal commitments of confidence applied, how well is the special nature of official statistics discussed and understood within various levels of the organisation? - This kind of situation may appear, for example, in the case of ONAs, or other national organisations than the national statistical office producing official statistics.

\section{The changing data ecosystem and statistical offices}

The fourth perspective describes the situation growing more and more relevant as the statistical offices are widening their scope of work. Already now, in addition to official statistics, the end products delivered to the users include many other types of information and data sets. Such tasks and services might increase in the future as the data and information ecosystems, and simultaneously the roles of various actors and organisations - also those of statistical offices - evolve.

For example, various studies, analyses and combined statistical insights are part of the service portfolio of many statistical offices. These can be combinations of previously released information or totally new and fresh information sets. These products and deliveries are not necessarily considered official statistics, and thus the principles of official statistics do not necessarily by def- inition apply to them. The question is how the principles of official statistics - principles about quality measures, transparency, timeliness, independency, simultaneous release and pre-release practices of information - are being applied to these kinds of products and services. Or are they?

In many cases, pre-lease under embargo, or some other practice, would be most beneficial and practical. In these cases, the challenge is how to differentiate between official statistics and other information products in order not to harm the overall reputation and image of the statistical office, and not to blur and impair the special role and practices of official statistics.

Another perspective regarding the widening role of statistical offices is related to their role as data offices or data brokers, a development happening in many countries. In addition to analysed, aggregated information statistical offices have begun to provide users with micro data - naturally taking data confidentiality and privacy protection into account. When are the micro data to be released for research and other purposes? Only after the statistical products based on them have been released, or earlier? One statement sometimes heard is "what if we give the data to be used by others, and they produce information products based on them faster than we can... and the users forget us." The truth is that new actors are approaching the data markets and challenging the role of official statistics. The competition is real.

This aspect grows more and more relevant as the number of data sources used by statistical offices increases, and a growing share of data used and managed by the statistical offices has primarily been collected for other than statistical purposes.

\section{Conclusions and considerations}

All in all, the data ecosystem is undergoing a change. This change inevitably affects the domain of official statistics, too. There are plenty of issues and aspects to be thought through and reconsidered, one of them being the questions related to release practices. Based on the experiences from Statistics Finland, some conclusions could be drawn:

- The question about embargo or pre-release is not only black and white but has many aspects to consider. Most probably the discussion about the issue will continue and grow in spectrum.

- If statistical offices only protect, set limits and safeguard their profession, principles, products, and practices, there is a risk that they might little by little protect official statistics and themselves as their producers to death. 
- But if statistical offices do not protect the conventional values of their profession, the continuity and existence of the special nature and value of official statistics might be endangered.

- Whatever the solutions are, the key element is to find and maintain a balance between the changing user needs, confidentiality of data, the main statistical principles, without messing up the trustworthiness and values of the statistical office.

Finally, it can also be asked whether it is time to start to evaluate and transform the current system of official statistics in order to be able to do it proactively and in a controlled way. We are, and we want to be, an essential part of the modern data ecosystem.

\section{References}

[1] European Statistical System: Quality Assurance Framework of the European Statistical System, 2019. https://ec.europa.eu/ eurostat/documents/64157/4392716/ESS-QAF-V1-2final.pdf/ bbf5970c-1adf-46c8-afc3-58ce177a0646.

[2] Eurostat: European statistics Code of Practice - revised edition 2017, 2017. https://ec.europa.eu/eurostat/documents/4031688/ 8971242/KS-02-18-142-EN-N.pdf/e7f85f07-91db-43128118-f729c75878c7.

[3] Ministry of Finance: Government report on information policy and artificial intelligence, 2018. https://vm.fi/documents/10623 /7768305/VM_Tiepo_selonteko_070219_ENG_WEB.pdf/89b 99a8e-01a3-91e3-6ada-38056451ad3f/VM_Tiepo_selonteko_ 070219_ENG_WEB.pdf.pdf/VM_Tiepo_selonteko_070219_ ENG_WEB.pdf.

[4] Statistics Finland: Guidelines on the confidentiality and disclosure of statistical data prior to their release, 2016. http://www. stat.fi/static/media/uploads/org/periaatteet/ohje_salassapito_ 2016_en.pdf. 